\title{
Twelve tips for effective crisis response in medical education institutions: Lessons learned from COVID-19
}

\begin{abstract}
:
Medical education is facing great challenges and uncertainties amidst the COVID-19 pandemic. Medical Education Institutions are required to build a task force team for crisis management. These should be committed to supporting a sudden online education transition, academic support, and psychological well-being of students, staff members, health care professionals, paramedics, and faculty administration.
\end{abstract}

As the situation evolves, the task force has to monitor the challenges and provide appropriate plans, guidance, and solutions.

Leaders in medical education have a crucial role in response to the pandemic crisis in securing a successful educational process while ensuring the mental and psychological well-being of the stakeholders.

Herein, we provide tips that can provide a guide for medical education leaders to coordinate crisis management.

Keywords: Academic Leadership, Change Management, Educational Leadership, Leadership, Leadership Development

\section{Background}

COVID-19 pandemic has been a major disruptor for medical education worldwide. However, it can be considered as an opportunity for developing innovative methodologies. Hereby, we are forced to rely on technology enhanced learning (TEL) (Ahmed et al 2020). During crisis situations, Medical educators' ethical responsibilities to act as effective leaders have come into sharper focus more than ever. They must be mindful of their own, institutional, and stakeholders' strengths and weaknesses. Teamwork is essential to the open discussion about the challenges and concerns on facing the pandemic. Medical educators are required to take innovative steps to build online programs and curricula through strategic planning.

Whatever your position is in your institution, Administrative, Coordinator, Head of a committee, Head of a department, or Module Coordinator, you should have a vision towards planning a response for crisis management. The senior leader must transmit a sense of urgency, unify work teams and prioritize the goals.

This work aims at offering a guiding document with tips to help people in responsibility manage their response to future crises effectively. 


\section{Tip 1:}

\section{Strategize on crisis management}

During the crises and trouble times, higher education institutions have to plan strategically to face different types of risks (Kotler and Murphy 1981). Risks must be anticipated and risk mitigation plans must be put into action once the institution is exposed. Health professions education institutions are in special need to have such strategic plans because of the unique nature of the subjects they teach, which require immediate actions to guarantee the delivery and assessment of skills-related learning outcomes. Plans should include proposed actions to address the undelivered and compromised learning outcomes and the way in which they will be compensated for in the future. An example would be compensation for missed clinical competences of clerkship years in the internship year under the supervision of the institution.

\section{Tip 2:}

\section{Build response teams}

Build a team for each response scenario assigning individuals using their job description and posts rather than their names. This team's plans/decisions should grant a fast track to the decision making and executives' bodies within the institute with a clear policy that contains a time frame for approving its decisions and putting them into action (Lerner et al 2009). Teams should contain members based on the scenario yet most probably including:

- Heads of departments

- Director of Education

- Director of assessment

- Data collection team (from the quality assurance unit)

- Student body representative (more than one body should be represented and make sure you have a balanced student representation)

- Communication team (including media spokesman)

- Psychiatric support team with trained students who can provide peer support in the times of crisis.

- Conflict resolution committee

- Documentation team

- External members to be added to the response team based on the nature of the crisis encountered (Carney et al 2011)

\section{Tip 3:}

\section{Communicate effectively}

a. Stakeholder analysis and mapping: understanding the internal and external stakeholders is a crucial step in managing the educational crisis situation. This will be a steppingstone towards identification of methods of communication and 
towards satisfaction of imminent needs of individuals and organizations affected by or affecting the situation.

b. Design of a communication strategy: this is a document that identifies methods by which the stakeholders will be kept up to date with all the implementation steps taken. This document is expected to set guidelines for methods of communication, structure, and expected outcomes from each method. In addition to this, a time plan can be added to this strategy document offering a complete plan. Many methods of communication can be used including applications like WhatsApp for rapid feedback and prompt corrective action (Carney et al 2011)

c. Assign the communication strategy to a taskforce: This is a very important step to ensure the communication plan becomes the responsibility of a team. They will be responsible for timely implementation of the identified communication methods as per the identified time plan.

d. Launch the communication plan considering

i. Communicating the vision-sense of urgency- to the decision makers (Dean)

ii. Communication with the stakeholders inside and outside the institution.

iii. Communicating the vision to the visionary heads of departments

iv. Transmission of the vision to the staff members (growth of the alliance)

e. Transmission of the vision to the supporting bodies of medical education (e.g. the Supreme council of Universities, Medical education sector, Other Medical schools, etc.)

f. Manage the relationship with the media: The relationship with the media will define how smooth the crisis resolution will be performed (Stassen 2010). Media messages are identified and approved in a hierarchical fashion and approval of all media messages is the responsibility of the communication team, when managing the relationship with the media take care you need to:

i. Provide a platform for daily communication

ii. Ensure accessibility for all the students and staff members

iii. Set an announced agenda for media encounters

\section{Tip 4:}

\section{Mobilize existing contingency plans}

a. Assess the available contingency response plan (Carney et al 2011)

i. Assign a review committee

ii. Map the strengths and weaknesses in the system

iii. Score the plan based on the threat grade of the situation; can be done through a scorecard used by evaluators that contain numerical evaluations based on evaluated areas and indicators (Table 1). The score card can also contain an open-ended item column for suggested reform areas and possible solutions.

b. Redesign the plan based on needs of the incident 
i. Outline the action steps based on the identified strengths and weaknesses and the possible solutions found in the evaluator scorecard responses.

ii. Action steps should include both the academic and the non-academic concerns.

iii. Special focus should be given to hospital related educational issues and the action steps taken that concern hospital administration and/or patients

c. Kick off the contingency plan in a meeting with task leaders

d. Map deliverables and milestones and map out the decisions needed to be made in the next 15 days, 30 days, 60 days, and 90 days.

Table 1: Template Evaluator Contingency Plan Scorecard

\begin{tabular}{|c|c|c|c|}
\hline $\begin{array}{l}\text { Contingency } \\
\text { Plan Subset }\end{array}$ & Accepted & $\begin{array}{l}\text { Rejected (needs } \\
\text { elimination) }\end{array}$ & $\begin{array}{l}\text { Suggested } \\
\text { Correction }\end{array}$ \\
\hline Objectives & $\begin{array}{c}\text { Mark only if the subset is } \\
\text { accepted without any } \\
\text { suggested correction }\end{array}$ & $\begin{array}{l}\text { Mark only if the } \\
\text { subset needs to be } \\
\text { redesigned }\end{array}$ & $\begin{array}{l}\text { Write down the } \\
\text { recommended } \\
\text { change if any }\end{array}$ \\
\hline Methods & $\begin{array}{c}\text { Mark only if the subset is } \\
\text { accepted without any } \\
\text { suggested correction }\end{array}$ & $\begin{array}{l}\text { Mark only if the } \\
\text { subset needs to be } \\
\text { redesigned }\end{array}$ & $\begin{array}{l}\text { Write down the } \\
\text { recommended } \\
\text { change if any }\end{array}$ \\
\hline Evaluation & $\begin{array}{c}\text { Mark only if the subset is } \\
\text { accepted without any } \\
\text { suggested correction }\end{array}$ & $\begin{array}{l}\text { Mark only if the } \\
\text { subset needs to be } \\
\text { redesigned }\end{array}$ & $\begin{array}{l}\text { Write down the } \\
\text { recommended } \\
\text { change if any }\end{array}$ \\
\hline Etc. & $\begin{array}{c}\text { Mark only if the subset is } \\
\text { accepted without any } \\
\text { suggested correction }\end{array}$ & $\begin{array}{l}\text { Mark only if the } \\
\text { subset needs to be } \\
\text { redesigned }\end{array}$ & $\begin{array}{l}\text { Write down the } \\
\text { recommended } \\
\text { change if any }\end{array}$ \\
\hline
\end{tabular}

Tip 5:

Engage students in every step 
a. An opened channel between the staff coordinators and students' representatives should be available (preferably WhatsApp for rapid feedback) (Alberson et al 2017).

b. Regular meetings with the students' representatives to communicate the vision, the implemented plan, and strategies.

c. Engage the students in the process to acquire a sense of ownership for the implemented plan.

d. Receive regular feedback for prompt corrective actions.

e. Keep an eye on the vulnerable groups.

i. Lower-income students who struggle internet accessibility should be identified and proactively supported

ii. Students that have been already academically struggling should be identified and receive extra support.

iii. The international students have additional concerns including obstacles to return home, accommodation, internet access, social, and academic struggles. Continual communication with the international students' representatives is essential to solve their issues

\section{Tip 6:}

\section{Align for Consensus and decision making}

An important step in managing the crisis is the degree of commitment to decision making and the timeliness of this process. Decisions made at time of crisis should be made by consensus and make sure that a complete democratic yet pace keeping leadership style is used. All decisions made during times of crisis are guided by a set of principles:

a. All decisions have to abide by standards of equity and are very well calibrated.

b. All decisions should be taken in close proximity to your students and faculty.

c. Make sure that your thoughts and decisions are made with an eye set outside the university walls as the decisions taken in the time of crisis are affected and affect the world around the university.

d. Both consistency and coordination are the cornerstone to proper, in-time decision making.

e. It is important to act with urgency and make sure you keep the time lines but also make sure you have a perspective and a vision that sets itself to the post crisis era and not just to overcome the crisis (Samarasekera et al 2020).

\section{Tip 7:}

\section{Utilize resources to respond to faculty, administration, and student needs}

a. Define and plan for the logistical needs (extra requirements such as providing internet access to the low-income students, allow free internet packages for the junior staff, etc.). 
b. Ultimate use of available resources of the Faculty and the same University with the aid of the student support groups (both at national level or at the level of the University) (Ahmed et al 2020)

c. Provide the safety measures for the clinical staff, residents, interns, alumni, and clinical-year students.

d. Provide the updated guidelines from the ministry of health and the WHO.

e. Training staff members.

f. Provide technical support for the staff members and the students' coordinators.

\section{Tip 8:}

\section{Resolve emerging conflicts}

In times of crisis conflicts will arise due to several factors many of which are related to the feeling of insecurity. Conflicts also arise when roles and expectations are not clear. Conflict resolution is the responsibility of the conflict resolution team and should be done timely and without delay. It is inadvisable to overlook any minor conflicts.

a. Expect conflicts and communicate this with your team at an early stage.

b. Embrace conflict understanding that conflict could add to the richness of the proposed solutions and are a gateway to open meaningful discussions.

c. Listen carefully to opposing views and evaluate the perception of your colleagues.

d. Communicate the vision and make sure you get buy in from all sides of the conflict.

e. Find solution and offer alternatives bearing in mind conflict management grid.

\section{Tip 9:}

\section{Support for institutional well-being}

Understand the true nature of the crisis and make sure you understand the impact and potential pressures that exist on your faculty, administration and students. Students at medical schools have scored up to $30 \%$ prevalence in suicidal ideation in some studies (Ahmed et al 2016). This puts a lot of emphasis on the importance of mentorship and close follow up of our students during the crisis.

Supporting the mental health of students and faculty who suffer from isolation, blurred vision, fears, and difficult family situations is essential.

a. Communicate with the psychiatry support team and announce contacts of the psychiatry team for psychological support for the students and staff

b. Provide online awareness sessions for mental health that are uploaded.

c. Organizing online informal meetings with the Coordinators for psychological support and answering the students' queries.

d. Regular online office hours for academic support and to keep in touch with the students. 


\section{Tip 10:}

\section{Appreciate the best practice}

At times of crisis, it is important to celebrate best practices and identify principles that work best. Celebration in times of crisis should not be held solely in relevance to milestones or deliverables. The morale of the team should be the first priority when making celebratory decisions. As we say catch your team doing something well and celebrate it on any given occasion.

a. Documentation of the best practice by staff members.

b. Encourage sharing the experience through educational videos, or fast track publications.

c. Documentation of students' best practice, by appreciation certificates.

d. Encourage the engagement of students in documenting the best practice through creating videos or sharing their perception and reflection to webinars, meetings and publications.

\section{Tip 11:}

\section{Be aware of your own needs}

Being in a position of responsibility makes you prone to pressure, and all types of health issues that are related to stress. Make a practice out of checking in with yourself every day to make sure that you acknowledge your negative feelings and are perceptive of your physical and psychological needs. Create a coalition of supporters around you and make sure you are in connection with them daily. Having people around you who know you and your capacities well is very important to help you realize when it is that you need support the most.

\section{Tip 12:}

\section{Document for the future}

The collective brains of institutions grow and develop with experience (Muthukrishna and Henrich 2016). The challenge that exists in every experience is an added value for the traditional depth of wisdom that exists in the institutional decision-making capacity. Amid crisis make sure that your institution has developed a strategy to document the roots of decisions made throughout it. Documentation through filing has long been the practice of choice. We propose a more robust documentation process where all processes are documented together with the root cause for each decision. This can be done through timely appreciative interviews with decision makers and video taping the experience. At the end a documentary of all decisions and how they were made can be made together with an institutional reflective practice on their perception of the crisis response. 


\section{Conclusions:}

We need to make the best use of the current COVID-19 situation in raising institutional readiness for crisis management in the future. This paper offers tips for Medical institutions that could be of help (Table 2).

\section{Table 2: Daily Checklist for leaders during Crisis Management}

\section{Checklist:}

- Have you checked in with the disaster response team today?

- Have you revised the media message for today?

- Have you checked your Gantt chart and identified necessary executive steps?

- How satisfied are your students today? How different are they feeling from yesterday and why? Is there anything you can do to make diffuse and situation that emerged?

- What is the status of wellbeing of your institution? Who needs support? Is there anything you can do to make the status of wellbeing better?

- What decisions need to be made today? How will they affect the stakeholders? Will you be able to defend these decisions once you make them?

- Is there any conflict emerging today? What will your directions be to the conflict resolution committee?

- Have you identified good practices for today? How will you celebrate them?

- Have you checked in with yourself? How are you feeling? What kind of support do you need?

\section{Highlights}

- Managing higher education institutions regarding crisis require a new set of skills.

- There are twelve areas to focus during crisis.

- It is recommended to use a daily checklist to follow-up the work stream. 
Acknowledgement: None.

Conflict of interest: The authors report no declarations.

Funding: Authors disclose no funding sources.

Ethics Statement: Ethical approval was not required as this article is an opinion piece, based on the authors' experience.

\section{References}

1. Ahmed S, Shehata M, Hassanien M. 2020. Emerging Faculty Needs for Enhancing Student Engagement on a Virtual Platform. MedEdPublish. 9(1):75.

2. Ahmed SA, Omar QH, Abo Elamaim AA. 2016. Forensic analysis of suicidal ideation among medical students of Egypt: A cross sectional study. J Forensic Legal Med. 44:1-4.

3. Alberson K, Arora VM, Zier K, Wolfson RK. 2017. Goals of medical students participating in scholarly concentration programmes. Med Educ. 51(8):852-860.

4. Carney J, Schilling L, Frank S, Biddinger P, Bertsch T, Grace C, Finkelstein J. 2011. Planning and Incorporating Public Health Preparedness into the Medical Curriculum. Am J Prev Med. 41(4S3):S193-S199.

5. Kotler P, Murphy PE. 1981. Strategic Planning for Higher Education. J High Edu. 52(5):470-489.

6. Lerner S, Magrane D, Friedman E. 2009. Teaching teamwork in medical education. Mt Sinai J Med. 76(4):318-329.

7. Samarasekera D, Goh D, Yeo S, Ngiam N, Marion M, Lim M, Pillai S, Lee SS, Mahadevan M, Kow A, Chong YS, Lau TC. 2020. Response and Lessons Learnt Managing the COVID-19 Crisis by School of Medicine, National University of Singapore. MedEdPublish. 9(1):92.

8. Stassen W. 2010. Your news in 140 characters: exploring the role of social media in journalism. Global Media J African Ed. 4(1):1-16.

9. Muthukrishna M, Henrich J. 2016 Innovation in the collective brain. Phil. Trans. R. Soc. B. 371.

\section{Notes on Contributors:}

Samar A. Ahmed, Medical Doctorate, MHPE, FAIMER Fellow, UNESCO TOT. Full professor in Forensic Medicine Ain Shams University, Director of ASU-MENA-FRI. She 
has a wide experience in project management and proposal writing after being a part of the Ministry of Higher Education EU project team for quite some time. She held many educational positions as a director of the quality assurance unit and the Director of the education development unit in more than one university. http://orcid.org/0000-00018119-9258

Mohamed Hany K. Shehata, Msc, MD, MHPE, FAIMER Fellow. Professor of Family Medicine - AGU. Faculty in EMR Regional FAIMER Institute. He founded the Medical Education Unit in Helwan University. Worked as educational consultant in the Egyptian Fellowship. In Suez Canal University he led the school\&\#39; teams of field training, Clinical teaching and OSCE. https://orcid.org/0000-0001-7069-9329

Raymond L Wells, PhD. Strengths-based leadership development and education. Facilitator for positive change throughout the East Coast. Greater Philadelphia Area. Associate Director, FAIMER Institute/Foundation for the Advancement of International Medical Education and Research, duration 20 years. President of Wellbeing Systems, Inc. since 1995 (Employment duration 25 years), Abington, PA.

Hani Atwa, MD, MHPE, PhD. Associate Professor of Medical Education at both Suez Canal University in Egypt and Ibn Sina National College for Medical Studies in Saudi Arabia. https://orcid.org/0000-0002-0099-4100

Hebat Allah A. Amin, MSc, MD, AICPD, FAIMER Fellow 2020. Lecturer of Histopathology, the Academic Co-chair of the Steering Committee for the MBBCh program, phase I coordinator, Head of the E-Learning Committee, and member in the exam Committee and the medical education unit, Faculty of Medicine, Helwan University (FMHU). http://orcid.org/0000-0003-3311-4840 